\title{
Modelling inhibitory effects of long chain fatty acids in the anaerobic digestion process
}

\author{
Ž. Zonta ${ }^{a, b}$, M.M. Alves ${ }^{c}$, X. Flotats ${ }^{a, b}$, J. Palatsi ${ }^{a, *}$ \\ ${ }^{a}$ IRTA, GIRO Joint Research Unit IRTA-UPC, Torre Marimon, E-08140 Caldes de Montbui, Barcelona, Spain \\ ${ }^{b}$ Dept. of Agrifood Engineering and Biotechnology, Universitat Politècnica de Catalunya (UPC), Parc Mediterrani de la Tecnologia, Edifici D-4, \\ E-08860 Castelldefels, Barcelona, Spain \\ ${ }^{\mathrm{C}}$ IBB - Institute for Biotechnology and Bioengineering, Centre of Biological Engineering, University of Minho, Campus de Gualtar, \\ 4710-57 Braga, Portugal
}

\section{A R T I C L E I N F O}

Article history:

Received 30 July 2012

Received in revised form

3 December 2012

Accepted 5 December 2012

Available online 19 December 2012

Keywords:

Anaerobic digestion

LCFA inhibition

Mathematical modelling

ADM1

\begin{abstract}
A B S T R A C T
Mathematical modelling of anaerobic digestion process has been used to give new insights regarding dynamics of the long chain fatty acids (LCFA) inhibition. Previously published experimental data, including batch tests with clay mineral bentonite additions, were used for parameter identification. New kinetics were considered to describe the bio-physics of the inhibitory process, including: i) adsorption of LCFA over granular biomass and ii) specific LCFA substrate (saturated/unsaturated) and LCFA-degrading populations. Furthermore, iii) a new variable was introduced to describe the state of damage of the acetoclastic methanogens in order to account for the loss of cell-functionality (inhibition) induced by the adsorbed LCFAs. The proposed model modifications are state compatible and easy to be integrated into the International Water Association's Anaerobic Digestion Model $N^{\circ} 1$ (ADM1) framework. Practical identifiability of model parameters was assessed with a global sensitivity analysis, while calibration and model structure validation were performed on independent data sets. A reliable simulation of the LCFA-inhibition process can be achieved, if the model includes the description of the adsorptive nature of the LCFAs and the LCFA-damage over specific biomass. The importance of microbial population structure (saturated/unsaturated LCFA-degraders) and the high sensitivity of acetoclastic population to LCFA are evidenced, providing a plausible explanation of experimental based hypothesis.
\end{abstract}

() 2012 Elsevier Ltd. All rights reserved.

\section{Introduction}

Long chain fatty acids (LCFAs) are the main intermediate byproduct of the lipid degradation process, and their accumulation in anaerobic digesters has been related with problems of sludge flotation, biomass washout and inhibition of the microbial activity (Rinzema et al., 1994). The cell-membrane seems to be the prime common target for most of the described LCFA inhibitory effects over anaerobic biomass. According to Kim and Gadd (2008), cell-membrane exposure to high concentrations of LCFA promotes macromolecular crowding and disruption of mechanisms such as protonmotive-force, DNA-docking and ATP-chemosynthesis. Impairment in nutrient uptake or inhibition of specific enzyme activity was also reported (Desbois and Smith, 2010). Pereira et al. $(2004,2005)$ have proven that the LCFA inhibition

\footnotetext{
* Corresponding author. Tel.: +34 938654350x1336; fax: +34 938650954.

E-mail address: jordi.palatsi@irta.cat (J. Palatsi). 
was reversible and also that the LCFA inhibition was related to physical transport limitation effects. The irreversible celldamage, due to the adsorption of LCFA, was discarded after this evidence and new technological perspectives emerged for the high-rate anaerobic treatment of wastewater containing lipids (Alves et al., 2009).

Several studies have discussed the addition of competing adsorbents into systems treating grease and fats as a possible strategy to limit LCFA inhibitory effects (Angelidaki et al., 1999; Beccari et al., 1999; Nielsen and Ahring, 2006; Palatsi et al., 2009). However, the dynamics of the solid-liquid adsorption process were not included in those studies and approximations to the LCFA-inhibition process (ratio inhibitor/biomass) were considered only (Pereira et al., 2004; Palatsi et al., 2010).

Up to day, Hwu et al. (1998) have proposed one of the most detailed descriptions of the LCFA's bio-sorption, degradation and inhibition processes. The LCFA inhibitory process was described based on a four-phase theoretical model. First, after a LCFA-pulse or biomass exposure, the LCFA rapidly disappears from the aqueous phase and is adsorbed onto the solid phase. Because of the LCFA-toxicity effect, the methane production is negligible during this phase. Second, depending on the initial LCFA-pulse concentration, the LCFAconcentration could increase in the aqueous phase, as a consequence of desorption mediated by the initial methane produced. Third, the LCFA-concentration decreases in the aqueous phase as a consequence of the biological degradation of the adsorbed LCFA. Finally, methane is ultimately recovered once the remaining LCFA-adsorbed concentration is low. Also, recent advances in molecular microbial ecology have brought new insights on the specific microorganisms that are involved in the $\beta$-oxidation process and the syntrophic methanogens interactions (Hatamoto et al., 2007; Sousa et al., 2007). Those microorganisms are not always abundant in nonadapted systems and their dynamics are not easy to follow. In this context, mathematical models are a valuable tool to be used to interpret collected data and to test new hypotheses.

Despite the fact that LCFA-inhibition is well documented and has a significant impact on the anaerobic digestion process, this phenomenon has not been included still in the ADM1 reference model (Batstone et al., 2002). In other developed models, LCFA inhibition is mainly modelled as a non-competitive process on the lipolytic, acidogenic or methanogenic activities (Angelidaki et al., 1999; Salminen et al., 2000; Lokshina et al., 2003). The commonly used noncompetitive inhibition functions (Angelidaki et al., 1999; Palatsi et al., 2010) implicitly assume that, after a LCFA-shock, the time to restore cell-functionality is negligible. It has been demonstrated that methanogens can adapt in several ways the structure and dynamics of their damaged membranes after an inhibitory effect (Valentine, 2007), but not immediately. Consequently, those classical model approximations may result inappropriate to simulate heavily LCFA-inhibited systems. Furthermore, the physical adsorption of LCFA and its inhibitory effect, or the microbiological aspects of LCFA-degradation, remain poorly characterized for modelling purposes. To the best of our knowledge, a mathematical model that includes adsorption-inhibition-degradation processes remains still to be defined and tested.
This paper aims to propose a LCFA-inhibition sub-model with the condition to be easily integrated into the ADM1model. This new approach tries to integrate all the previously reported knowledge about LCFA inhibitory process, regarding the adsorptive nature and transport limitations of LCFA, the new insights on microorganisms involved in $\beta$-oxidation process and the possible membrane damage caused by LCFA exposure. Proposed model will be tested with two independent data sets obtained in previous batch experiments (Palatsi et al., 2012).

\section{Material and methods}

\subsection{Experimental observations}

Previously published experimental data were used for parameter identification. The experimental set-up consisted of several specific batch tests performed with two different anaerobic granular sludges (sludge-A and sludge- $B$, or independent data sets), including bentonite addition as a synthetic adsorbent, and synthetic sodium oleate as substrate. The experimental set-up and analytical methods are extensively described in Palatsi et al. (2012). The experimental observations were grouped in three main data-sets, summarized as follows:

Data set $\mathrm{D}_{1}$ : LCFA-adsorption batch tests with chemically inactivated biomass (sludge-A) and bentonite, monitoring the time evolution of soluble-LCFA concentrations (LCFA $)$.

Data set $D_{2}$ : Methanogenic activity test (SMA) with sludgeA $\left(D_{2, A}\right)$ and sludge- $B\left(D_{2, B}\right)$ with acetate $(A c)$ and hydrogen $\left(H_{2}\right)$ as biogas formation substrates, monitoring the accumulated methane production in vials head-space $\left(\mathrm{CH}_{4}\right)$. In addition, blank assays with sludge-A and sludge-B (vials with biomass but without added substrates) were also monitored.

Data set $D_{3}$ : Batch-tests with increasing LCFAconcentrations and specific batch-tests including preventing/recovering LCFA inhibition strategies, where bentonite was added as an exogenous adsorbent. The experiments with sludge- $A\left(D_{3, A}\right)$ included vials with bentonite addition after the LCFA-pulse ( $T_{A}$ vials). The experiments with sludge- $B\left(D_{3, B}\right)$ included vials with a bentonite-LCFA mixed compound added to the LCFA-free biomass ( $T_{B}$ vials), to prevent inhibition. Control vials with LCFA, but without bentonite, were also considered for both tested biomass $\left(C_{A}\right.$ and $C_{B}$ vials). SolidLCFA (LCFA $A_{s}$ ), liquid-LCFA (LCFA $A_{1}$ ), volatile fatty acids (VFA) and methane production $\left(\mathrm{CH}_{4}\right)$ measurements were adopted for system monitoring.

\subsection{Model development}

The developed models were based on a simplification of the anaerobic digestion process as described in the ADM1 model. The same structure, nomenclature and units of the ADM1 model were used (Batstone et al., 2002). The first proposed model, LCFA-M1, included the LCFA-adsorption process and non-competitive inhibition functions. The second model, LCFA-M2, also included a new variable called healthy-state that considers the LCFA-inhibitory stage of methanogenic biomass. The models were implemented in MatLab (The Mathworks, 
Table 1 - Stoichiometric matrix for the proposed LCFA-inhibition models. Processes $P_{k}, k=1,2, \ldots, 15$, are reported in Table 2.

\begin{tabular}{|c|c|c|c|c|c|c|c|c|c|c|c|c|c|c|c|}
\hline State & $\mathrm{P}_{1}$ & $\mathrm{P}_{2}$ & $\mathrm{P}_{3}$ & $\mathrm{P}_{4}$ & $\mathrm{P}_{5}$ & $\mathrm{P}_{6}$ & $\mathrm{P}_{7}$ & $\mathrm{P}_{8}$ & $\mathrm{P}_{9}$ & $\mathrm{P}_{10}$ & $\mathrm{P}_{11}$ & $\mathrm{P}_{12}$ & $\mathrm{P}_{13}$ & $\mathrm{P}_{14}$ & $\mathrm{P}_{15}$ \\
\hline $\mathrm{S}_{\mathrm{c} 18, \mathrm{l}}$ & -1 & -1 & & & & & & & & & & & & & \\
\hline $\mathrm{S}_{\mathrm{c} 18, \mathrm{~s}}$ & 1 & & $\begin{array}{l}\left(1-Y_{f a}\right) \\
\left(1-\beta_{a c}-\beta_{h 2}\right)\end{array}$ & -1 & & & & & & & & & & & \\
\hline $\mathrm{S}_{\mathrm{c} 18, \mathrm{ben}}$ & & 1 & -1 & & & & & & & & & & & & \\
\hline$S_{c 16, l}$ & & & & & -1 & -1 & & & & & & & & & \\
\hline$S_{c 16, s}$ & & & & $\begin{array}{l}\left(1-Y_{f a}\right) \\
\left(1-\beta_{a c}-\beta_{h 2}\right)\end{array}$ & 1 & & $\begin{array}{l}\left(1-Y_{f a}\right) \\
\left(1-\beta_{a c}-\beta_{h 2}\right)\end{array}$ & -1 & & & & & & & \\
\hline$S_{c 16, \text { ben }}$ & & & & & & 1 & -1 & & & & & & & & \\
\hline $\mathrm{S}_{a c, 1}$ & & & $\left(1-Y_{f a}\right) \beta_{a c}$ & $\left(1-Y_{f a}\right) \beta_{a c}$ & & & $\left(1-Y_{f a}\right) \beta_{a c}$ & $\begin{array}{l}(1-\alpha) \\
\left(1-Y_{f a}\right)\end{array}$ & -1 & & & & & & $0.8\left(1-f_{x i}\right)$ \\
\hline$S_{h 2, l}$ & & & $\left(1-Y_{f a}\right) \beta_{h 2}$ & $\left(1-Y_{f a}\right) \beta_{h 2}$ & & & $\left(1-Y_{f a}\right) \beta_{h 2}$ & $\alpha\left(1-Y_{f a}\right)$ & & -1 & & & & & $0.2\left(1-f_{x i}\right)$ \\
\hline $\mathrm{S}_{\mathrm{ch} 4, \mathrm{l}}$ & & & & & & & & & $\left(1-Y_{a c}\right)$ & $\left(1-Y_{h 2}\right)$ & & & & & \\
\hline $\mathrm{X}_{\mathrm{c} 18}$ & & & $\mathrm{Y}_{f a}$ & $Y_{f a}$ & & & & & & & -1 & & & & \\
\hline $\mathrm{X}_{\mathrm{c} 16}$ & & & & & & & $Y_{f a}$ & $Y_{f a}$ & & & & -1 & & & \\
\hline$X_{a c}$ & & & & & & & & & $Y_{a c}$ & & & & -1 & & \\
\hline$X_{h 2}$ & & & & & & & & & & $Y_{h 2}$ & & & & -1 & \\
\hline$X_{\mathrm{dec}}$ & & & & & & & & & & & 1 & 1 & 1 & 1 & -1 \\
\hline$X_{i}$ & & & & & & & & & & & & & & & $f_{x i}$ \\
\hline
\end{tabular}

USA) within the Simulink Cmex-coded environment. The stoichiometric matrix and the process-associated kinetic rates are indicated in Tables 1 and 2, respectively. A scheme of the simplified anaerobic digestion model is presented in Fig. 1, based on the following assumptions:

LCFA $\left(S_{f a}\right)$, acetate $\left(S_{a c}\right)$, hydrogen $\left(S_{h 2}\right)$ and methane $\left(S_{c h 4}\right)$ were considered as the main model components, in order to keep the structure of the model simple. Thus, $S_{a c}$ and $S_{h 2}$ were the only products of the $\beta$-oxidation process of LCFA $\left(\mathrm{P}_{4}\right.$ and $\mathrm{P}_{8}$ in Tables 1 and 2). No other particulate substrates such as lipids $\left(\mathrm{X}_{\mathrm{li}}\right)$, proteins $\left(\mathrm{X}_{\mathrm{pr}}\right)$ and carbohydrates $\left(\mathrm{X}_{\mathrm{ch}}\right)$, or process intermediates such as butyrate $\left(S_{b u}\right)$, valerate $\left(S_{v a}\right)$ or propionate $\left(S_{\text {pro }}\right)$ were considered, in accordance with the experimental results (low detected values by Palatsi et al., 2012).
Consequently, particulate decayed biomass $X_{\text {dec }}$ was considered as storage for all minor intermediates and other possible slowly biodegradable-substrates. $\mathrm{X}_{\mathrm{dec}}$ was estimated for each experimental design by the COD mass balance of the system. It was assumed that $1 \mathrm{gCOD}$ of $\mathrm{X}_{\mathrm{dec}}$ is converted through hydrolysis, considering that acidogenesis is a fast process and hydrolysis the rate limiting step, to 0.56 gCOD of acetate $\left(S_{a c}\right)$, 0.14 gCOD of hydrogen $\left(S_{h 2}\right)$, and to 0.30 gCOD of inerts $\left(X_{i}\right)$. A first-order reaction was assumed for the hydrolysis process of $\mathrm{X}_{\mathrm{dec}}\left(\mathrm{P}_{15}\right.$, in Tables 1 and 2$)$, being $k_{\text {hyd }}$ the hydrolysis constant.

The total LCFA concentration, $S_{f a}$, was split into oleate, $S_{c 18}$, and palmitate, $S_{\mathrm{c} 16}$, since palmitate has been proposed to be the main intermediate during the anaerobic degradation of oleate (Lalman and Bagley, 2001; Pereira et al., 2002). Moreover,

\section{Table 2 - Processes $P_{k}$ associated with the stoichiometric matrix of Table 1.}

\begin{tabular}{|c|c|c|}
\hline$k$ & Process, $\mathrm{P}_{k}$ & 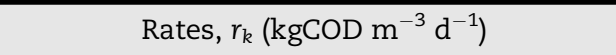 \\
\hline 1 & $\mathrm{~S}_{\mathrm{c} 18, \mathrm{l}}$ adsorption over biomass & $k_{\text {ads,bio }} \cdot S_{\mathrm{c} 18, l} \cdot\left(q_{\text {sat,bio }} \cdot X_{\text {bio }}-S_{c 18, s}\right)-k_{\text {des,bio }} \cdot S_{c 18, s}$ \\
\hline 2 & $\mathrm{~S}_{\mathrm{c} 18, \mathrm{l}}$ adsorption over bentonite & $k_{\mathrm{ads}, \text { ben }} \cdot \mathrm{S}_{\mathrm{c} 18, \mathrm{l}} \cdot\left(q_{\mathrm{sat}, \text { ben }} \cdot X_{\mathrm{ben}}-\mathrm{S}_{\mathrm{c} 18, \mathrm{ben}}\right)-k_{\mathrm{des}, \text { ben }} \cdot \mathrm{S}_{\mathrm{c} 18, \mathrm{ben}}$ \\
\hline 3 & $\mathrm{~S}_{\mathrm{c} 18 \text {,ben }}$ biological desorption from bentonite & $k_{m, f a} \cdot \frac{S_{c 18, \text { ben }}}{K_{\mathrm{S}, f a}+S_{c 18, \text { ben }}} \cdot X_{\mathrm{c} 18} \cdot I_{h 2} \cdot I_{X f a}$ \\
\hline 4 & $\mathrm{~S}_{\mathrm{c} 18, \mathrm{~s}}$ degradation & $k_{m, f a} \cdot \frac{S_{\mathrm{c} 18, \text { bio }}}{K_{\mathrm{S}, f a}+S_{\mathrm{c} 18, \mathrm{bio}}} \cdot \mathrm{X}_{\mathrm{c} 18} \cdot I_{\mathrm{h} 2} \cdot \mathrm{I}_{\mathrm{Xfa}}$ \\
\hline 5 & $S_{\mathrm{c} 16, l}$ adsorption over biomass & $k_{\text {ads,bio }} \cdot S_{\mathrm{c} 16, l} \cdot\left(q_{\text {sat,bio }} \cdot X_{\text {bio }}-S_{\mathrm{c} 16, \mathrm{~s}}\right)-k_{\text {des,ben }} \cdot S_{\mathrm{c} 18, \text { ben }}$ \\
\hline 6 & $\mathrm{~S}_{\mathrm{c} 16,1}$ adsorption over bentonite & $k_{\text {ads,ben }} \cdot S_{\mathrm{c} 16, l} \cdot\left(q_{\text {sat,ben }} \cdot X_{\text {ben }}-S_{c 16, \text { ben }}\right)-k_{\text {des,ben }} \cdot S_{c 16, \text { ben }}$ \\
\hline 7 & $\mathrm{~S}_{\mathrm{c} 16, \text { ben }}$ biological desorption from bentonite & $k_{m, f a} \cdot \frac{S_{c 16, \text { ben }}}{K_{S, f a}+S_{c 16, \text { ben }}} \cdot X_{\mathrm{c} 16} \cdot I_{h 2} \cdot I_{X f a}$ \\
\hline 8 & $\mathrm{~S}_{\mathrm{c} 16, \mathrm{~s}}$ degradation & $k_{m, f a} \cdot \frac{S_{c 16, \text { bio }}}{K_{S, f a}+S_{c 16, \text { bio }}} \cdot X_{c 16} \cdot I_{h 2} \cdot I_{X f a}$ \\
\hline 9 & $\mathrm{~S}_{a c}$ degradation & $k_{m, a c} \cdot \frac{S_{a c}}{K_{S, a c}+S_{a c}} \cdot X_{a c} \cdot I_{X a c}$ \\
\hline 10 & $\mathrm{~S}_{\mathrm{h} 2}$ degradation & $k_{m, h 2} \cdot \frac{S_{h 2}}{K_{S, h 2}+S_{h 2}} \cdot X_{h 2}$ \\
\hline 11 & $\mathrm{X}_{\mathrm{c} 18}$ decay & $k_{\mathrm{dec}} \cdot X_{\mathrm{c} 18}$ \\
\hline 12 & $\mathrm{X}_{\mathrm{c} 16}$ decay & $k_{\mathrm{dec}} \cdot \mathrm{X}_{\mathrm{c} 16}$ \\
\hline 13 & $\mathrm{X}_{\mathrm{ac}}$ decay & $k_{\mathrm{dec}} \cdot X_{a c}$ \\
\hline 14 & $\mathrm{X}_{\mathrm{h} 2}$ decay & $k_{\mathrm{dec}} \cdot X_{h 2}$ \\
\hline 15 & $X_{\text {dec }}$ slowly-biodegradable recirculation & $k_{\text {hyd }} \cdot X_{\text {dec }} \cdot I_{X f a}$ \\
\hline
\end{tabular}




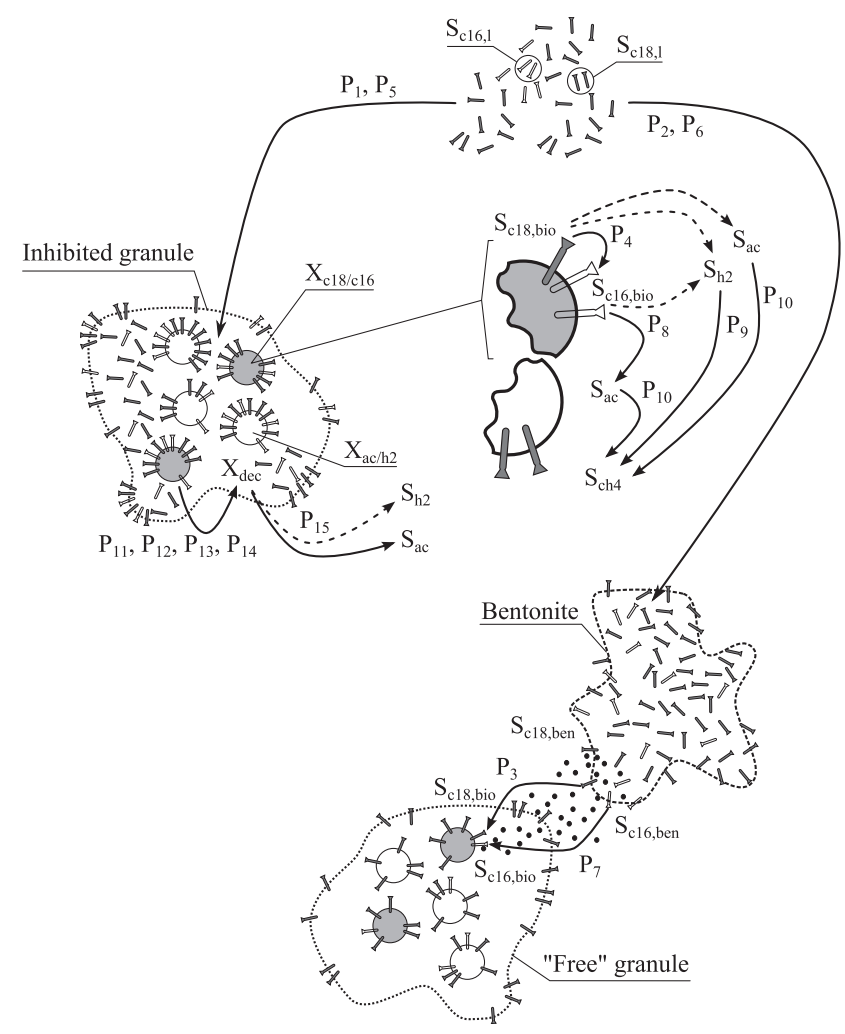

Fig. 1 - Process scheme of the assumed LCFA-adsorption and degradation pathway with/without clay mineral (bentonite) addition as an exogenous adsorbent. Processes $P_{k}$ are represented, where $X_{c 18} / X_{c 16}$ are the oleate/palmitate degraders, $X_{a c} / X_{h 2}$ are the methanogens and $X_{d e c}$ is the decayed biomass and the considered slowly biodegradable substrate. The LCFA-substrates are the oleate/ palmitate present in the liquid $\left(\mathrm{S}_{\mathrm{c} 18, \mathrm{l}} / \mathrm{S}_{\mathrm{c} 16, \mathrm{l}}\right)$, adsorbed on biomass $\left(\mathrm{S}_{\mathrm{c} 18, \mathrm{bio}} / \mathrm{S}_{\mathrm{c16}, \mathrm{bio}}\right)$ and on bentonite $\left(\mathrm{S}_{\mathrm{c} 18, \mathrm{ben}} / \mathrm{S}_{\mathrm{c} 16, \mathrm{ben}}\right)$.

during oleate degradation $\left(\mathrm{P}_{4}\right)$ in the present experiments, palmitate was detected accumulating onto biomass (Palatsi et al., 2012). Consequently, oleate and palmitate can be found free in liquid media $\left(S_{c 18, l}\right.$ or $\left.S_{c 16, l}\right)$ or adsorbed onto biomass $\left(S_{c 18, \text { bio }}\right.$ or $\left.S_{c 16, b i o}\right)$ and bentonite $\left(S_{c 18, b e n}\right.$ or $\left.S_{c 16, b e n}\right)$, when this clay-mineral is added to the media as an exogenous adsorbent (Palatsi et al., 2012).

According to Hwu et al. (1998), the LCFA adsorption onto anaerobic biomass $\left(S_{f a, s}\right)$ is described as a pre-requisite for its biological degradation ( $\mathrm{P}_{1}$ and $\mathrm{P}_{5}$ in Tables 1 and 2). As previously stated, the LCFA-adsorption process over bentonite was also considered ( $\mathrm{P}_{2}$ and $\mathrm{P}_{6}$ in Tables 1 and 2). For simplicity, desorption from solid to liquid was assumed only dependent on the adsorbed LCFA-concentration, $\mathrm{S}_{f a, s}$. The liquid-solid transport dynamics were approximated by a Langmuir adsorption isotherm kinetic (Mouneimne et al., 2004), which was expressed by the following general process rate (equation (1)), for the processes $P_{1}, P_{2}, P_{5}$ and $P_{6}$ (in Table 2):

$r_{k}=k_{\text {ads }} S_{f a, l}\left(q_{\text {sat }} X_{\text {ads }}-S_{f a, s}\right)-k_{\text {des }} S_{f a, s}, k=1,2,4,6$,

where $S_{f a, s}$ and $S_{f a, l}$ are respectively the LCFA concentration in the solid and the liquid phase, $k_{\mathrm{ads}}$ is the adsorption rate, $k_{\mathrm{des}}$ is the desorption rate, $X_{\text {ads }}$ is the adsorbent concentration, and $q_{\text {sat }}$ is the sorbate over adsorbent saturation coefficient. The considered adsorbents $\left(X_{\mathrm{ads}}\right)$ were bentonite $\left(X_{\text {ben }}\right)$ and granular sludge $\left(\mathrm{X}_{\mathrm{bio}}\right)$. The notation of LCFA concentration adsorbed only on bentonite (or biomass) is $\mathrm{S}_{f a \text {,ben }}$ (or $\mathrm{S}_{f a, b i o}$ ), while the LCFA adsorbed over all the present solids is written as $S_{f a, s}$. Adsorption interaction effects between bentonite-biomass $\left(X_{\text {bio }}-X_{\text {ben }}\right)$ or between the multiple components present in the liquid-solid system $\left(X_{\mathrm{bio}}-X_{\mathrm{ben}}-S_{f a, s}\right)$ were not considered in the current adsorption-model. The concentration of the overall biomass-adsorbent $\mathrm{X}_{\text {bio }}$ was considered time-variable, since it is the sum of specific substrate-degraders (e.g., $X_{f a}, X_{a c}$, $X_{h 2}$, etc.), inerts $\left(X_{i}\right)$ and the slowly-biodegradable matter $\left(X_{\text {dec }}\right)$. On the other hand, $X_{\text {ben }}$ was assumed constant whenever it was used.

Biological $\beta$-oxidation process was also considered (process $\mathrm{P}_{3}$ and $\mathrm{P}_{7}$ in Tables 1 and 2 ) in order to model the transference of the adsorbed LCFA on bentonite $\left(S_{f a, b e n}\right)$ to biomass $\left(\mathrm{S}_{f a, b i o}\right)$. Exo-enzymatic activity was assumed to be mediated by the LCFA-degraders, since they may grow on the outermost shell of the biomass granule (Picioreanu et al., 2005), in direct contact with the surface of bentonite.

Two different groups of specific LCFA-degrader microorganisms $\left(X_{f a}\right)$ were considered: i) the oleate-degraders, $X_{c 18}$, and ii) the palmitate-degraders, $X_{c 16}$. Sousa et al. (2008) reported that oleate/palmitate-degrading cultures showed different microbial composition, concluding that the community structure in a reactor might depend on the saturation degree of the LCFA-feed and that not all the $\beta$-oxidative degraders have the ability to degrade both saturated (e.g., $S_{c 16}$ ) and unsaturated (e.g., $\mathrm{S}_{\mathrm{c} 18}$ ) fatty acids.

A non-competitive inhibition function of LCFA over the $\beta$-oxidizing population $\left(X_{\mathrm{c} 18}\right.$ or $\left.\mathrm{X}_{\mathrm{c} 16}\right)$ was considered, defined as (equation (2)):

$I_{\mathrm{Xfa}}=K_{\mathrm{Xfa}}\left(K_{\mathrm{Xfa}}+\mathrm{S}_{f a, b i o}\right)^{-1}$,

where $K_{x f a}$ is the inhibitory concentration coefficient and $S_{f a, b i o}$ is the LCFA adsorbed onto the biomass. It was assumed that only $S_{f a, b i o}$ causes LCFA-inhibition, since other possible LCFA-species such as $S_{f a, l}$ or $S_{f a \text {,ben }}$ are not involved in the disruption of the cell-functionality. The non-competitive LCFA-inhibition function $I_{x f a}$ (equation (2)) was also considered as an inhibitory function for the hydrolysis process $\left(\mathrm{P}_{15}\right.$ in Table 2), as suggested by Angelidaki et al. (1999).

According to Hanaki et al. (1981), aceticlastic methanogens (process $\mathrm{P}_{10}$ in Tables 1 and 2 ) are probably the most LCFA-affected microorganisms. Thus, for the aceticlastic population, a secondary non-competitive LCFA-inhibition function was assumed (Salminen et al., 2000; Lokshina et al., 2003), defined as (equation (3)):

$I_{\text {Xac }}=I_{\text {Xac,noncomp }}=K_{\text {Xac }}\left(K_{\text {Xac }}+S_{\text {fa,bio }}\right)^{-1}$,

where $K_{x a c}$ is the corresponding inhibitory concentration coefficient. Here, the LCFA-inhibition function $I_{x a c}$ (equation (3)) was used in the first proposed version of the LCFAinhibition model (LCFA-M1).

As an alternative to the standard LCFA-inhibition function of equation (3), a second model for the LCFA-inhibition process of the aceticlastic population (LCFA-M2) was 
proposed. In LCFA-M2 a new variable was introduced, $H_{\mathrm{xac}}$, called healthy-state of the aceticlastic population $\left(X_{a c}\right)$, which is defined with the following differential equation and an initial condition, being $H_{x a c}=1$ at $t=0$ if biomass has not been previously in touch with LCFA (equation (4)):

$\frac{d H_{\text {Xac }}}{d t}=r_{\text {max }} \cdot\left(1-H_{\text {Xac }}\right)-S_{f a, b i o} \cdot H_{\text {Xac }} ; H_{\text {Xac }}=1, t=0$,

where $r_{\max }$ is the maximum cell recovery rate. The healthy state $H_{x a c}$ is defined within a finite range $[0,1]$ : i) if $H_{x a c}$ equals one, the average functionality of the cell is then optimal (methanogenic pathway is active); while ii) if $H_{x a c}$ equals zero then the cell is severely damaged and the methanogenic pathway is interrupted (diverted to other cell-maintenance/ recovery pathways). The cell-damage, $D_{x a c}$, can be quantified as $D_{\text {xac }}=1-H_{\text {xac }}$. The rate of recovery depends on the level of damage of the cell (first term on the right-hand side of equation (4)). If the cell is badly damaged, the recovery rate is then maximal. The damage (second term on the right-hand side of equation (4)) depends directly on the present value of $S_{f a, b i o}$ and $H_{\mathrm{xac}}$. If the LCFA-adsorbed concentration on the biomass is high, then the damage to the cell is also high. However, if $\mathrm{H}_{\mathrm{xac}}$ is close to zero, no further damage is then possible. When the healthy-state equals zero $\left(H_{\mathrm{xac}}=0\right)$ it does not mean that biomass has reached a state of decay. In the present study, the rate of decay of the biomass is independent of $\mathrm{H}_{\mathrm{xac}}$. It was assumed that under extreme environmental pressure (highLCFA concentrations) the acetoclastic population becomes resilient to LCFA-damages because of its possible biochemical adaptation (Shin et al., 2003; Valentine, 2007) and its increased effort to restore the cell functionality (i.e., increase of the recovery rate term). Acetoclastic microorganisms are assumed to switch from "survival-mode" to "methanogenicmode" only when its cell-functionality is restored to a given level. However, the LCFA-inhibition function should be a smooth function, since it is an averaged measure of the overall acetoclastic population transition from the survival to the normal functionality mode. Among many possible switching smooth functions, we propose the simple powerlaw function as the LCFA-inhibition function for the acetoclastic, defined as (equation (5)):

$\mathrm{I}_{\mathrm{Xac}}=\mathrm{I}_{\mathrm{Xac}, \text { healthy }}=\mathrm{H}_{\mathrm{Xac}}^{\gamma}$,

where $\gamma$ is the scaling exponent coefficient, which is restricted over the interval $[1,+\infty)$. Note that after a LCFA-shock, for a value of $\gamma$ higher than 1, the recovery of the methanogenic activity is fully re-activated only when the average celldamage is considerably reduced. Thus, the scaling exponent coefficient $\gamma$ gives an idea of how "healthy" the acetoclastic degraders should be in order to "switch" again to the "methanogenic-mode". Since $H_{x a c}$ is defined in the finite range $[0,1]$, $I_{\text {xac, healthy }}$ takes values in the finite range $[0,1]$.

Summarizing, the differences between LCFA-M1 and LCFAM2 are only in how the inhibition function $I_{\text {xac }}$ is defined:

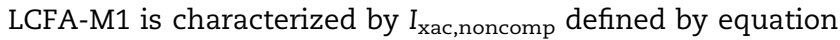
(3) (non-competitive inhibition), while LCFA-M2 is characterized by $I_{x a c, h e a l t h y}$ defined by equation (5) (inhibition expressed as function of the healthy state variable).

Contrary to other proposed models (Palatsi et al., 2010), no LCFA-inhibitory effect was considered for hydrogenotrophic methanogens (process $P_{9}$ in Table 1 and 2). This decision is supported by experimental evidence from activity tests over an LCFA-adsorbed (inhibited) biomass on vials fed with $\mathrm{H}_{2}$ (Pereira et al., 2005). These authors suggested that the diffusion of $\mathrm{H}_{2}$, through the LCFA-layer, was faster than for other substrates, because the low molecular weight. Thus, even if a concentration of LCFA was adsorbed over the biomass, vials fed with the $\mathrm{H}_{2}$-substrate immediately transformed this substrate into methane.

The following non-competitive inhibition function over the LCFA-degraders population by hydrogen accumulation was assumed (equation (6))

$I_{h 2}=K_{I, h 2}\left(K_{I, h 2}+S_{f a, b i o}\right)^{-1}$,

where $K_{I, h 2}$ is the corresponding inhibition constant, in order to account for the effect of a possible high partial pressure of hydrogen (Batstone et al., 2002).

\subsection{Practical identification and global sensitivity analysis}

The practical identifiability of parameters of a given model depends on the model-structure and on the evidence $\mathrm{D}$ (available data) with which the model is compared. A parameter's practical identifiably can be precisely assessed, within a global sensitivity analysis (SA), by studying how model-parameters affect a misfit function, 'J'. Performing a SA of $J$ involves the decomposition of its variance over the parameter-space. Variance-based methods (Sobol', 1976) are well suited to account for the parameter interactions when non-linear models are considered (Saltelli et al., 2010). A variance-based main effect for a generic parameter $\theta_{i}(i=1, \ldots, k)$ can be written as (equation (7)).

$\mathrm{V}_{\theta_{i}}\left(E_{\theta_{\sim i}}\left\{J \mid \theta_{i}\right\}\right)$,

where $\theta_{i}$ is the $i$-th parameter and $\theta_{\sim i}$ denotes the vector of all parameters but $\theta_{i}$. The meaning of the inner expectation operator, $E$, is that the mean of $J$ is taken, overall possible values of $\theta_{\sim i}$, while keeping $\theta_{i}$ fixed. The outer variance, $\mathrm{V}$, is taken overall possible values of $\theta_{i}$. When the main effect is normalized by the unconditional variance, $V(J)$, we obtain the associated sensitivity measure (main effect index, $S_{i}$ ) written as equation (8), according to Saltelli et al. (2010):

$S_{i}=\frac{\mathrm{V}_{\theta_{i}}\left(E_{\theta_{\sim i}}\left\{J \mid \theta_{i}\right\}\right)}{\mathrm{V}(J)}$

In a similar way, the first-order interaction effect index $\left(S_{i, j}\right)$ can be written as (equation (9)):

$S_{i, j}=\frac{V_{\theta_{i, j}}\left(E_{\theta_{\sim i, j}}\left\{J \mid \theta_{i, j}\right\}\right)}{V(J)}$.

Another popular variance based measure is the total effect index $\left(S_{\text {Ti }}\right)$, defined as (equation (10))

$S_{T i}=\frac{E_{\theta_{\sim i}}\left(V_{\theta_{i}}\left\{J \mid \boldsymbol{\theta}_{\sim i}\right\}\right)}{V(J)}=1-\frac{V_{\theta_{\sim i}}\left(E_{\theta_{i}}\left\{J \mid \boldsymbol{\theta}_{\sim i}\right\}\right)}{V(J)}$,

which measures the first and higher order effects (interactions) of the parameter $\theta_{i}$. In probabilistic SA, the parameter $\theta$ is a stochastic variable characterized by a distribution $g(\theta)$ that 
describes our prior assumptions over $\theta$. In the present work, two types of uncertainty parameter distributions $g(\theta)$, with its respective parameters $a$ and $b$, were used as needed: a uniform distribution, Unif $(a, b)$, and a normal distribution, $\operatorname{Norm}\left(a, b^{2}\right)$. When $g\left(\theta_{i}\right)$ was of an uniform-type, during modelcalibration (i.e., least-square function $J$ minimization), the parameter $\theta_{i}$ was constrained over a finite range interval given the relative uniform parameter interval $\left[a_{i}, b_{i}\right]$, whilst when it was of a normal-type, $\theta$ was constraint positive with a sixsigma (i.e. $6 \times b_{i}$ ) variation around its location parameter, $a_{i}$.

In the present study, a sum-of-squares misfit function $J(\theta$; D) was assumed. Weights relative to the number of samples and measurement-errors were not applied. Given that the number of $\mathrm{CH}_{4}$ samples was very high in relation to other measurements (e.g., Ac, LCFA $A_{s}$ and LCFA L $_{1}$ the fit to the methane production samples was implicitly prioritized. The SA was performed by a Bayesian sensitivity analysis tool for estimating the main, first-order and total effect indexes (Oakley and O'Hagan, 2004).

In order to give a quantitative estimation of parameter uncertainty, the parameter estimation error covariance matrix (Dochain and Vanrolleghem, 2001) was numerically approximated, from which confidence intervals (CI) were estimated and the Student statistical significance $t$-test were performed for $K_{\mathrm{xfa}}, K_{\mathrm{xac}}, r_{\max }, \gamma, X_{\mathrm{c} 18}$ and $X_{\mathrm{c} 16}$, since those parameters are the most relevant in our discussion. The commonly used assumption of normally distributed and independent measurement errors was assumed.

\subsection{Sequential model calibration}

The model-parameters vector $\theta$ was estimated by leastsquares (LS-estimates) using a "scatter-search" global optimization routine (Rodriguez-Fernandez et al., 2006). Since many different data sets were available (data set $D_{1}, D_{2, A}, D_{2, B}$, $D_{3, A}$ and $D_{3, B}$ ), the calibrations of the proposed models were performed in a sequential mode as explained below:

\subsubsection{LCFA-M1 model}

Step 1. Data set $D_{1}$ was used to determine the LS-estimate $\theta^{1}=\left[k_{\text {ads }}, q_{\text {sat }}, k_{\text {dis }}\right]\left(=\left[\theta_{1}^{1}, \theta_{2}^{1}, \theta_{3}^{1}\right]\right)$ for the LCFA-adsorption model of equation (1), since the experimental design was such that the adsorption process was independent from the biological process (inactivated biomass). The relative SA indices for $\theta^{1}$ were obtained conditional to a uniform distribution $g\left(\theta^{1}\right)$ where the $i$-th parameter was assumed independent.

Step 2. Data set $D_{2}$ was used to estimate the initial methanogenic populations $\left(X_{a c}\right.$ and $\left.X_{h 2}\right)$, the initial concentration of decayed biomass (initial $X_{\mathrm{dec}}$ ), and the first-order hydrolysis constant ( $k_{\text {hyd }}$ ) for sludge-A and sludge-B. Nominal values for the remaining model parameters $\left(k_{m, j}\right.$ and $\left.K_{\mathrm{S}, j}\right)$ - see supporting information Table $\mathrm{A}$ - were assumed according to Rosen and Jeppsson (2006). The parameter vector $\theta^{2}=\left[X_{\mathrm{dec}}\right.$, $X_{a c}, X_{h 2}, k_{\text {hyd }}$ ] was constrained over a finite range interval given by an assigned $g\left(\theta^{2}\right)$. Sensitivity indices were also calculated. Since the SMA assays were performed without LCFA in the vials, the parameters associated with the LCFA-inhibition process (e.g., $K_{\mathrm{xfa}}, K_{\mathrm{xac}}, \mathrm{X}_{\mathrm{c} 18}$ and $\mathrm{X}_{\mathrm{c} 16}$ ) cannot influence the misfit function $J$ during this step.

Step 3. The SA was performed over data set $D_{3, A}$ and $D_{3, B}$ in order to evaluate their relative quality for the estimation of

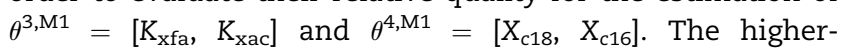
informative data set was used to calibrate $\theta^{3, \mathrm{M} 1}$ and $\theta^{4, \mathrm{M} 1}$

Step 4. The parameter vector $\theta^{3, \mathrm{M} 1}$, estimated within the higher-informative data set (Step 3), was used to decrease the under-determination of the lower-informative calibration scenario, that is, the SA was run in order to assess the information-gain. The LCFA-degrader initial concentration parameter vector $\theta^{4, \mathrm{M} 1}$ was estimated within the improved calibration scenario for the lower-informative data set. The idea was that the high-informative data set was used to calibrate the model, while the lower-informative data set was used to "semi-validate" the structure of the proposed model. When SA was performed over one sub-models at a time, it was possible to overlook interactions among parameters in different sub-models (type II error, i.e. assessing as nonimportant an important parameter).

\subsubsection{LCFA-M2 model}

The same sequential calibration mode was performed for the second proposed model LCFA-M2, with the sole difference that the parameter vectors $\theta^{3, \mathrm{M} 2}=\left[K_{\mathrm{xfa}} r_{\max } \gamma\right]$ and $\theta^{4, \mathrm{M} 2}=\left[\mathrm{X}_{\mathrm{c} 18}\right.$ $\mathrm{X}_{\mathrm{c} 16}$ ] were calibrated only for the higher-informative data set obtained in Step 3.

\section{Results and discussion}

\subsection{Initial parameter estimation}

The experimental design was such that data sets $D_{1}$ and $D_{2}$ were independent from the biological LCFA degradationinhibition process (focus of the present study), or independent from any included ADM1 model modifications (LCFA-M1/ LCFA-M2). Consequently, the calibration of $\theta^{1}$ and $\theta^{2}$ can be performed in a batch-mode and their values can be used in further data sets study. LS-estimates and the sensitivity indices for parameter vectors $\theta^{1}$ and $\theta^{2}$ are summarized in supporting information (Table $\mathrm{B}$ and $\mathrm{C}$, respectively).

From adsorption/desorption estimated parameters (Table $B$, in supporting information), it can be observed that the saturation coefficient $\left(q_{\text {sat }}\right)$ for bentonite is higher than for inactivated biomass, and of the same order of magnitude of those estimated by Palatsi et al. (2012) fitting a Langmuir isotherm model. Therefore, bentonite seems to be a better adsorbent media than inactivated biomass, although with estimated saturation coefficients with wide CIs. Few conclusions can be obtained from the estimated adsorption/ desorption rate coefficients ( $k_{\mathrm{ads}}$ and $k_{\mathrm{des}}$ respectively) according to the sensitivity analysis results. Although the obtained values are in accordance with other studies (Mouneimne et al., 2004), it appears that there is not enough data-information in order to accurately estimate the values of $k_{\mathrm{ads}}$ and $k_{\mathrm{des}}$, as a result of the comparison of main and total effect indexes, $S_{i}$ and $S_{T i}$, and the wide CIs obtained in Table B. 
Although those limitations, the effect of this underdetermination over further modelling (data sets $D_{3}$ ) could be considered negligible over LCFA degradation rates, since physical adsorption-desorption process is very fast if compared with the biological degradation, but important to explain the bentonite addition effect.

Single methanogenic activity tests with acetate and hydrogen (data set $\mathrm{D}_{2}$ ), including controls, are not providing enough data for $\theta^{2}$ parameter estimation, since estimated initial population concentrations $\left(X_{i}\right)$ are fully correlated with process coefficients $\left(k_{m, i}\right.$ and $\left.K_{S, i}\right)$. The problem of underdetermination was reduced by assuming the values of the ADM1's maximum uptake rates and the half saturation constants of the involved anaerobic biomass populations (Rosen and Jeppsson, 2006), as reported in the supporting information (Table A). Resulting sensitivity indexes and LSestimates for parameter vector $\theta^{2}$ are also summarized in the supporting information section (Table C). As expected, with the imposed assumptions, the main effect index, $S_{i}$, explains almost all the variance of the misfit function $J$, which implies that the parameter vector $\theta^{2}$ can be accurately determined. Estimated initial biomass concentration in SMA tests for sludge-A was slightly higher than for sludge-B (see supporting information, Table $\mathrm{C}$ ). Contrarily, the residual slowlybiodegradable organic-matter, $X_{\mathrm{dec}}$, is significantly lower for sludge-A than for sludge- $B$ (see supporting information, Table $C)$, according to its different origin and storage conditions, that is, stored or fresh granules obtained from running brewery or fruit juice industry UASB reactors, respectively (Palatsi et al., 2012).

\subsection{Data set selection for LCFA-M1 calibration}

The relative sensitivity analysis indices $\left(S_{i}\right.$ and $\left.S_{T i}\right)$ for parameters $K_{\mathrm{xfa}}, K_{\mathrm{xac}}, \mathrm{X}_{\mathrm{c} 18}$ and $\mathrm{X}_{\mathrm{c} 16}$ were reported in Table 3. $\mathrm{SA}$ indices are conditional on their relative data sets $\mathrm{D}_{3, \mathrm{~A}}$ and $D_{3, B}$. Ratto et al. (2001) proposed general guidelines to assess the practical identifiability of model-parameters: i) parameters with a high main effect (high $S_{i}$ ) affect J singularly, irrespective of interactions and thus can be considered precisely estimated; ii) parameters with a small main $\left(S_{i}\right)$ and total effect $\left(S_{T i}\right)$ have a negligible effect over $J$ and thus cannot be estimated precisely; iii) parameters with a small main effect $\left(S_{i}\right)$ but high total effect $\left(\mathrm{S}_{\mathrm{Ti}}\right)$ mainly affect $J$ through interactions.

The main and the interaction effects respectively explain $91.6 \%$ and $92.5 \%$ of the total misfit-function variance for data

Table 3 - Sensitivity indices of parameter vectors $\theta^{3, \mathrm{M} 1}$ and $\theta^{4, M 1}$ for sludge-A and sludge-B.

\begin{tabular}{lccrr} 
Parameter & Data set & $g(\theta)$ & \multicolumn{1}{c}{$\mathrm{S}_{\mathrm{i}}$} & \multicolumn{1}{c}{$\mathrm{S}_{\mathrm{Ti}}$} \\
\hline $\mathrm{K}_{\mathrm{xfa}}\left(\mathrm{kgCOD} \mathrm{m}^{-3}\right)$ & $\mathrm{D}_{3, \mathrm{~A}}$ & Unif $[1 \mathrm{e}-4,2]$ & 38.4 & 53.8 \\
$\mathrm{~K}_{\mathrm{xac}}\left(\mathrm{kgCOD} \mathrm{m}^{-3}\right)$ & $\mathrm{D}_{3, \mathrm{~A}}$ & Unif $[1 \mathrm{e}-4,2]$ & 1.4 & 9.2 \\
$\mathrm{X}_{\mathrm{c} 18}\left(\mathrm{kgCOD} \mathrm{m}^{-3}\right)$ & $\mathrm{D}_{3, \mathrm{~A}}$ & Unif $[1 \mathrm{e}-4,5]$ & 18.5 & 29.4 \\
$\mathrm{X}_{\mathrm{c} 16}\left(\mathrm{kgCOD} \mathrm{m}^{-3}\right)$ & $\mathrm{D}_{3, \mathrm{~A}}$ & Unif $[1 \mathrm{e}-4,5]$ & 24.6 & 35.1 \\
$\mathrm{~K}_{\mathrm{xfa}}\left(\mathrm{kgCOD} \mathrm{m}^{-3}\right)$ & $\mathrm{D}_{3, \mathrm{~B}}$ & Unif $[1 \mathrm{e}-4,2]$ & 35.4 & 71.8 \\
$\mathrm{~K}_{\mathrm{xac}}\left(\mathrm{kgCOD} \mathrm{m}^{-3}\right)$ & $\mathrm{D}_{3, \mathrm{~B}}$ & Unif $[1 \mathrm{e}-4,2]$ & 0.2 & 2.8 \\
$\mathrm{X}_{\mathrm{c} 18}\left(\mathrm{kgCOD} \mathrm{m}^{-3}\right)$ & $\mathrm{D}_{3, \mathrm{~B}}$ & Unif $[1 \mathrm{e}-4,5]$ & 11.8 & 27.9 \\
$\mathrm{X}_{\mathrm{c} 16}\left(\mathrm{kgCOD} \mathrm{m}^{-3}\right)$ & $\mathrm{D}_{3, \mathrm{~B}}$ & Unif $[1 \mathrm{e}-4,5]$ & 15.0 & 43.2 \\
\hline
\end{tabular}

set $D_{3, A}$ and $D_{3, B}$. The remaining variance is explained by higher-order interactions of parameters. We observe that the main effect indices $\left(S_{i}\right)$ relative to the parameter vector $\theta^{3, \mathrm{M} 1}$ are lower for data set $D_{3, B}$ than for data set $D_{3, A}$. It was also observed that for almost all the parameters the difference between $S_{i}$ and $S_{T i}$ was consistently higher for data set $D_{3, B}$ than for data set $D_{3, A}$, which implies that for data set $D_{3, B}$ the interaction effects between parameters are stronger than for data set $D_{3, A}$. Thus, given the above guidelines, we concluded that data set $D_{3, A}$ is more informative than data set $D_{3, B}$ and, therefore, the data set $D_{3, A}$ was used for the estimation of parameters associated with the LCFA-inhibition process $K_{\mathrm{xfa}}$ and $K_{\mathrm{xac}}$. The parameter vector $\theta^{3, \mathrm{M} 1}$ estimated with data set $\mathrm{D}_{3, \mathrm{~B}}$ can be considered unidentifiable, but still important in order to correctly fit data, since its total effect index is not negligible. From the above SA-results, it was decided to use the experimental design of sludge- $\mathrm{A}$, in order to estimate the parameter vector $\theta^{3, \mathrm{M} 1}$ for the LCFA-M1 model. Here, the discussion is limited by the model simulation outcomes and by the goodness of the fit, since data set $\mathrm{D}_{3, \mathrm{~A}}$-and $\mathrm{D}_{3, \mathrm{~B}}-$ was presented and discussed in detail in Palatsi et al. (2012).

\subsection{LCFA-M1 model calibration. Sludge-A}

Fig. 2 shows the simulation of the liquid-solid LCFA phases, the Ac concentrations and the $\mathrm{CH}_{4}$ production for the vials with bentonite addition $\mathrm{T}_{\mathrm{A}}$ (dash lines) and the control vial $\mathrm{C}_{\mathrm{A}}$ (continuous lines). The goodness of the fit is quantified within the root-mean squared-error (RMSE) statistic. Simulation results of the batch experiments with an increasing oleate concentration (also included in data set $\mathrm{D}_{3, \mathrm{~A}}$ ) are reported in the supporting information, Figure A. The LS-estimated parameters and the CIs are summarized in Table 4 . The performed Student's t-test indicates that parameters are significant in the model with a probability higher than $99 \%$

It can be observed, from Fig. 2, that the oleate concentration in the liquid $\left(\mathrm{C}_{18} \mathrm{l}_{\mathrm{l}}\right.$ ) is reasonably well described by the adsorption model (i.e., $\mathrm{S}_{\mathrm{c} 18, \mathrm{l}}$ model outcomes). The adsorption process was very fast when compared with the biologicalmediated process, as reported by Hwu et al. (1998). The sampling frequency of the measurements was insufficient to follow the fast-adsorption dynamics at the beginning of the experiment. The uncertainty of the adsorption-parameter vector $\theta^{1}$ can only slightly influence the misfit function value. Note that the estimation of parameter vector $\theta^{2}$ can be achieved with great accuracy also. Thus, we expect that the SA performed over parameter vectors $\theta^{3}$ and $\theta^{4}$ should lead to a negligible type II error.

According to Fig. 2,the model was able to reproduce an accumulation of oleate on the solid phase $\left(\mathrm{C} 18_{\mathrm{s}}\right)$. Oleate degradation was followed by a remarkable palmitate accumulation in the solid phase (C16s). Pereira et al. (2002) also identified palmitate as key intermediate species during oleate degradation in not-adapted systems. The simulated palmitate concentrations of LCFA-M1 were almost entirely found adsorbed onto biomass $\left(S_{\mathrm{c} 16, \mathrm{~s}} \approx \mathrm{S}_{\mathrm{c} 16 \text {, ben }}\right.$ since $\mathrm{S}_{\mathrm{c} 16, \text { ben }} \approx 0$ ), confirming observations of granules, performed under the microscope, on day 10 (Palatsi et al., 2012). According to the model simulation of LCFA-M1 for strategy $T_{A}$ and control $C_{A}$, it was observed that the $\mathrm{C} 16_{\text {bio }}$ concentration time evolution 

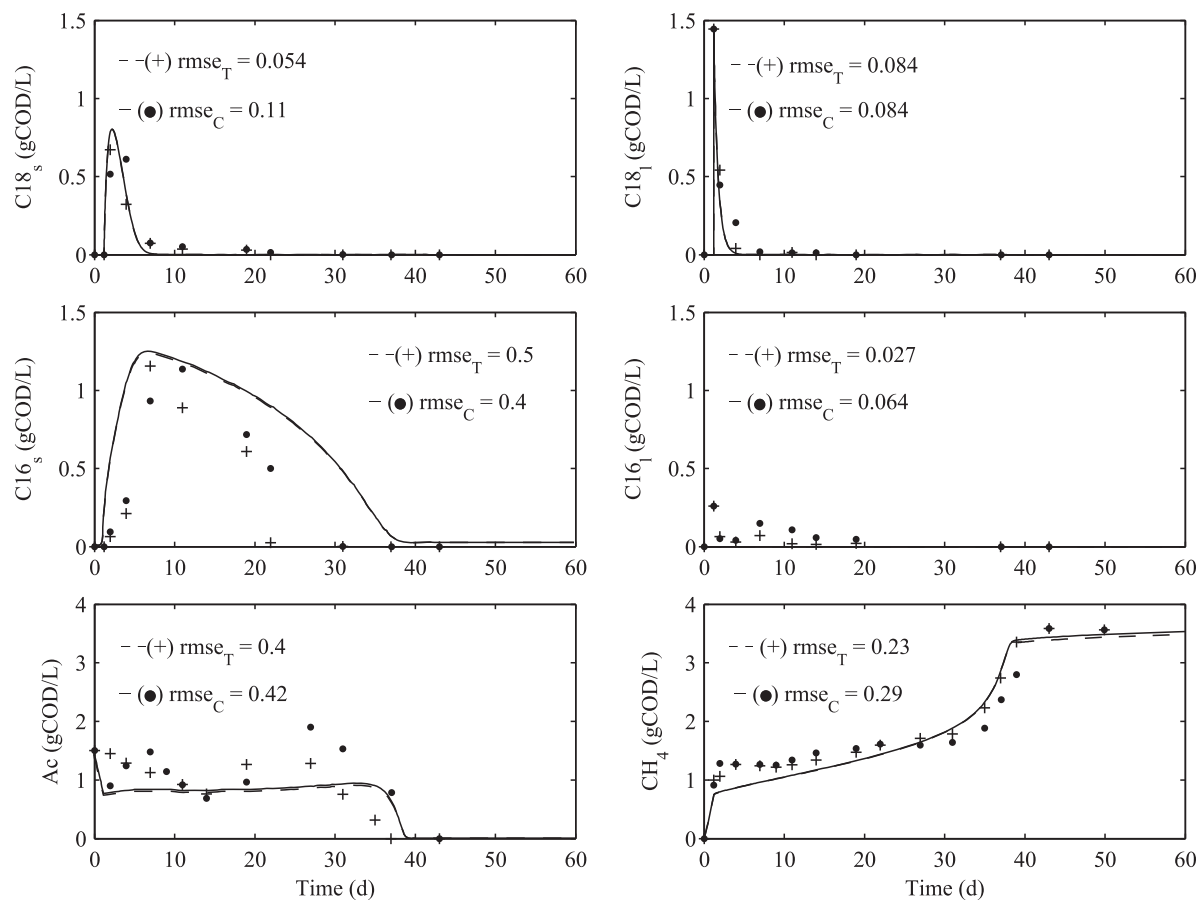

Fig. 2 - Calibration of the LCFA-M1 model with Sludge-A (data set $\left.D_{3, A}\right)$. The bentonite addition $\left(T_{A}\right)$ model-outcome (dash line) and observations (cross dots) are compared with the control-experiment $\left(C_{A}\right)$ model-outcome (continuous line) and observations (circle dots).

was approximately the same. This evidenced that the strategy tested in $\mathrm{T}_{\mathrm{A}}$ vials (bentonite addition after LCFA pulse) was not efficient in LCFA-inhibition prevention.

The main problem arising with the LCFA-M1 model was the poor data-fit of the accumulation process of $\mathrm{C16}$ s (see Fig. 2). In fact, the modelled degradation of $\mathrm{C} 16_{\mathrm{s}}$ suffered a delay of almost 10 days (i.e., approximately from day 25 to day 35) if compared with experimental data. Note that the misfit function favours the fit of the $\mathrm{CH}_{4}$ measurements, according to more available data. Consequently, in order to properly fit the $\mathrm{CH}_{4}$ measurements, the LCFA-M1 model artificially extends the LCFA-inhibition effect with a larger $\mathrm{C} 16_{\text {bio }}$ accumulation. The problem is that the inhibition function for the acetoclastic population $I_{\mathrm{xac}}$ (equation (3)) depends directly on the LCFA $A_{s}$ concentration present in the system.

It can be noted from Fig. 2 that residuals are quite autocorrelated because of the model-structure limitation of LCFA-M1. Since our error-model does not account for autocorrelated errors, the estimated CIs tend to be underestimated. This problem is independent of the inferential procedure used. In this case, future work is necessary in order to build a suitable error-model if a better quantitative

Table 4 - . LS-estimates and CIs of parameter vectors $\theta^{3, \mathrm{M} 1}$ and $\theta^{4, \mathrm{M} 1}$ for sludge-A (i.e. data set $\mathrm{D}_{3, \mathrm{~A}}$ ).

\begin{tabular}{lcc} 
Parameter & LS-value & CI-95\% \\
\hline $\mathrm{K}_{\mathrm{xfa}}\left(\mathrm{kgCOD} \mathrm{m}^{-3}\right)$ & 0.324 & \pm 0.245 \\
$\mathrm{~K}_{\mathrm{xac}}\left(\mathrm{kgCOD} \mathrm{m}^{-3}\right)$ & 0.045 & \pm 0.010 \\
$\mathrm{X}_{\mathrm{c} 18}\left(\mathrm{kgCOD} \mathrm{m}^{-3}\right)$ & 0.496 & \pm 0.089 \\
$\mathrm{X}_{\mathrm{c} 16}\left(\mathrm{kgCOD} \mathrm{m}^{-3}\right)$ & 0.020 & \pm 0.010 \\
\hline
\end{tabular}

estimation of parameter uncertainty is required. Despite the model-structure limitation of LCFA-M1, it can be concluded that it is still capable to reproduce the main trends of the system reasonably well. The LS-estimate for the LCFA-inhibition parameter of acidogenic-degraders, $K_{x f a}$, was of $0.324 \mathrm{kgCOD} \mathrm{m}^{-3}$ (Table 4), whilst the LCFA-inhibition parameter of acetoclastic-degraders, $K_{x a c}$, was of $0.045 \mathrm{kgCOD} \mathrm{\textrm {m } ^ { - 3 }}$. These results suggest that the acidogenic population was more sensitive to the LCFA-inhibition than the acetogenic population, in accordance with previous reports (Salminen et al., 2000; Lokshina et al., 2003; Palatsi et al., 2010). Also, according to the obtained model parameters, the initial LCFA-degraders structure was dominated by oleate-degraders $\mathrm{X}_{\mathrm{c} 18}$, creating a potential condition for a palmitateaccumulation which may lead to a long lasting LCFA inhibition of the system.

\subsection{LCFA-M1 model structure semi-validation. Sludge-B}

Should the two data sets $D_{3, A}$ and $D_{3, B}$ be obtained within the same sludge or biomass then a model validation would be possible. Since this is not the case, the LS-estimates of $\mathrm{X}_{\mathrm{c} 18}$ and $\mathrm{X}_{\mathrm{c} 16}$ for sludge-A cannot be used to validate the model over sludge-B data. However, we will use the improper name of "semi-validation" to refer the scenario where we calibrate $\theta^{4, \mathrm{M} 1}$ for sludge- $\mathrm{B}$, conditional on the parameter vector $\theta^{3, \mathrm{M} 1}$, which was calibrated for sludge-A (data set $D_{3, A}$ ). Hence, a strong assumption stating that for sludges of different origins the LCFA-inhibition effect depends only on the LCFA-population structure distribution was made, since the LCFA-resilience $\left(K_{\mathrm{xfa}}\right.$ and $\left.\mathrm{K}_{\mathrm{xac}}\right)$ of the biomass is approximately constant. 
Table 5 - Sensitivity indices, LS-estimates and CIs of parameter vectors $\theta^{3, \mathrm{M} 1}$ and $\theta^{4, \mathrm{M} 1}$ for sludge-B (i.e. data set $\mathrm{D}_{3, \mathrm{~B}}$ ). An informative SA scenario is considered, where parameter vector $\theta^{3, \mathrm{M} 1}$ is known (Table 4 values adopted), with a low degree of uncertainty, and modelled with a normal distribution $g\left(\theta^{3, \mathrm{M} 1}\right)$.

\begin{tabular}{|c|c|c|c|c|c|}
\hline Parameter & $g(\theta)$ & $S_{i}$ & $\mathrm{~S}_{\mathrm{Ti}}$ & LS-value & CI-95\% \\
\hline$K_{\mathrm{xfa}}\left(\mathrm{kgCOD} \mathrm{m}^{-3}\right)$ & $\operatorname{Norm}\left(0.324,0.023^{2}\right)$ & 1.1 & 7.9 & 0.324 & - \\
\hline$K_{\text {xac }}\left(\mathrm{kgCOD} \mathrm{m}^{-3}\right)$ & $\operatorname{Norm}\left(0.045,0.006^{2}\right)$ & 0.0 & 0.0 & 0.045 & - \\
\hline $\mathrm{X}_{\mathrm{c} 18}\left(\mathrm{kgCOD} \mathrm{m}^{-3}\right)$ & Unif $[1 e-4,5]$ & 48.6 & 67.7 & 0.067 & \pm 0.002 \\
\hline $\mathrm{X}_{\mathrm{c} 16}\left(\mathrm{kgCOD} \mathrm{m}^{-3}\right)$ & Unif $[1 e-4,5]$ & 29.1 & 49.5 & 0.242 & \pm 0.019 \\
\hline
\end{tabular}

Besides from performing the semi-validation of LCFA-M1, the lack of information of data set $\mathrm{D}_{3, \mathrm{~B}}$ (sludge- $\mathrm{B}$ ) can be improved when a perfect knowledge over parameter vector $\theta^{3, \mathrm{M} 1}$ is assumed. Since the sensitivity indices relative to $\theta^{3, \mathrm{M} 1}$ would be zero for this perfect-knowledge, SA-scenario, a small amount of uncertainty was added to $\theta^{3, \mathrm{M} 1}$. The uncertainty of $\theta^{3, \mathrm{M} 1}$ was modelled within a normal distribution. Table 5 summarizes the repeated SA for sludge-B observations and the corresponding CI for the LS-estimates. The Student's t-test indicates the high significance of the estimated parameters, with a probability higher than $99 \%$. It can be observed that the variance of the misfit function was mainly explained within the initial concentration of the LCFA-degraders $\left(X_{c 18}\right.$ and $\left.X_{c 16}\right)$. Likewise, the $S_{i}$ index improves (Table 5), while the $K_{x f a}$ interaction first-order effect with $X_{c 18}$ and $X_{c 16}$ decreases to just $2.9 \%$ (not shown in Table 5). If the values of $S_{i}$ relative to data set $D_{3, B}$, are compared between Tables 3 and 5 , it can be observed that the estimation-precision of parameters $X_{c 18}$ and $\mathrm{X}_{\mathrm{c} 16}$ was improved, when the a-priori information about $\mathrm{K}_{\mathrm{xfa}}$ and $K_{\text {xac }}$ rules out unrealistic possibilities. The model-fit to data of LCFA-M1 for the semi-validation scenario $\left(T_{B}\right.$ and $C_{B}$ vials of $\left.D_{3, B}\right)$ is represented in Fig. 3, while model-fit results of
LCFA-batch assays at increasing oleate concentrations are presented in the supporting information (Figure B).

Similarly as for sludge-A, the adsorption model cannot be evaluated because of the low sampling frequency; the low RMSE values for $\mathrm{C} 18_{l}$ and $\mathrm{C}_{16}$, should be considered with reserve. The simulated $\mathrm{LCFA}_{s}, \mathrm{~S}_{f a, s}$, was equivalent to the LCFA-bentonite adsorbed concentration, $S_{f a, b e n}$, since bentonite was mixed with the LCFA-inhibitory concentration before its addition to the anaerobic system (Palatsi et al., 2012). If the control experiment $\left(C_{B}\right)$ is considered, the simulation reproduces the $C 18_{s}$ and $C 16_{s}$ observations quite well, whilst if we consider the prevention-strategy experiment $\left(T_{B}\right)$, the model underestimates these data. Moreover, a relevant misfit for Ac data can be observed if the prevention-strategy experiment $\left(T_{B}\right)$ is considered: the $A c$ accumulation reproduced within the LCFA-M1 model was not detected by the measurements. The misfit of $\mathrm{C} 18_{s}$ and Ac were necessary in order to correctly reproduce the methane production measurements. Since the methane measurements were of high-fidelity (more available data, including batch assays with increasing oleate concentrations, $D_{3}$ ) the experimental results of $\mathrm{C} 18_{\mathrm{s}}$ and Ac at day 7 can reasonably be suspected of being
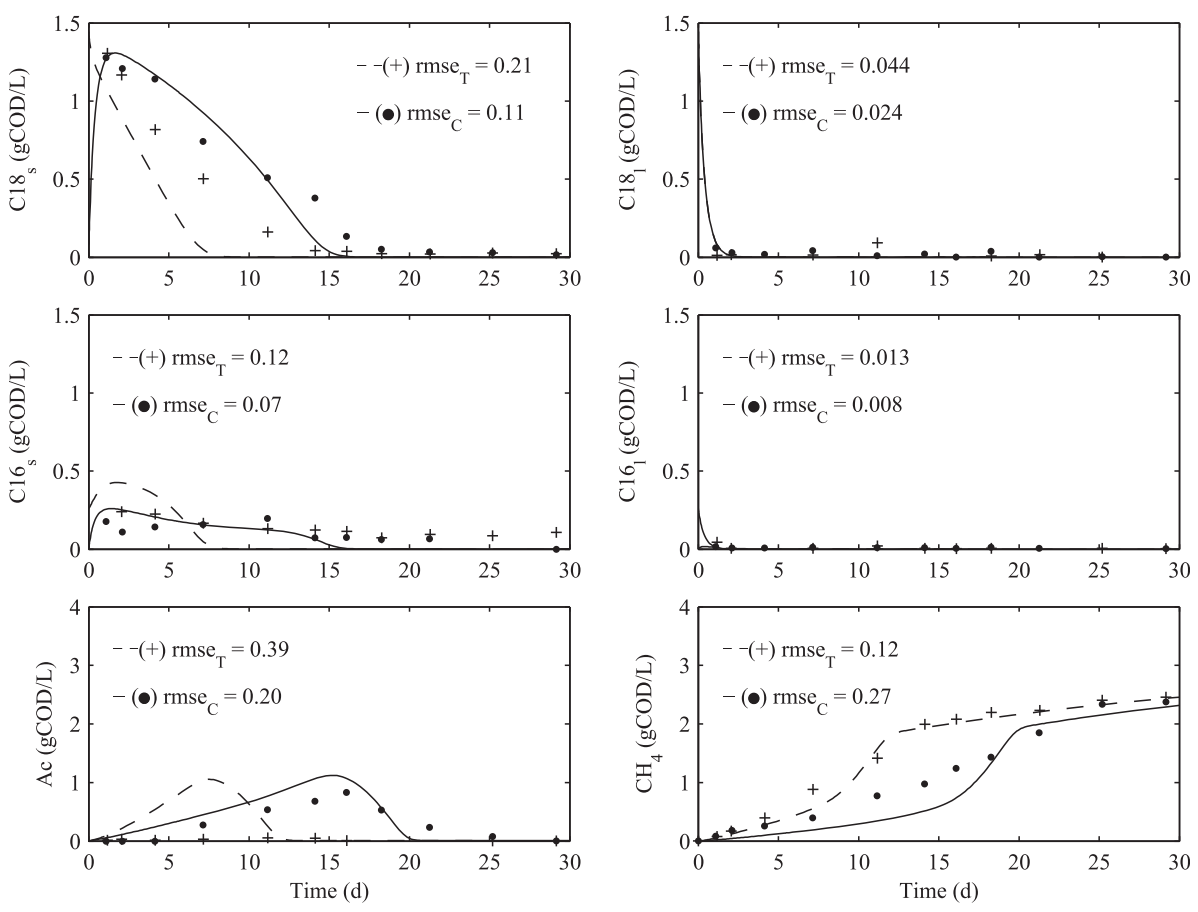

Fig. 3 - Semi-validation of the LCFA-M1 model with Sludge-B (data set $D_{3, B}$ ). The bentonite addition ( $T_{B}$ ) model-outcome (dash line) and observations (cross dots) are compared with the control-experiment $\left(C_{B}\right)$ model-outcome (continuous line) and observations (circle dots). 
erroneous (from COD balance). Note that $\mathrm{C} 18_{\mathrm{s}}$ and $\mathrm{Ac}$ measurements were conducted within a vial sacrifice (Palatsi et al., 2012) and thus, some experimental results might possibly be considered as outliers.

Considering sludge-B's informative scenario (Table 5), the LS-estimates for the initial concentration of $X_{\mathrm{c} 18}$ and $X_{c 16}$ were $0.067 \mathrm{kgCOD} \mathrm{m}^{-3}$ and $0.242 \mathrm{kgCOD} \mathrm{m}^{-3}$, respectively. The high concentration of palmitate-degraders population can explain in part the absence of a palmitate accumulation, as observed for sludge-A. During the molecular profiling of biomass A and B, by means of PCR-DGGE techniques (Palatsi et al., 2012), it was not possible to confirm this hypothesis. The results of process modelling now provide a new insight into the importance of the specific microbial structure of $\beta$-oxidative organisms. Note that the estimated $X_{\text {dec }}$ concentration for sludge- $B$ was higher than the $X_{\text {dec }}$ for sludge-A (supporting information Table $C$ ). This fact was previously pointed out by Pereira et al. (2004) and Palatsi et al. (2010) as a possible factor influencing the LCFA-degradation dynamics, since the presence of other biodegradable substrates (considered in $\mathrm{X}_{\mathrm{dec}}$ pull) may enhance LCFA-degradation rates (Kuang et al., 2006).

The LCFA-M1 model was able to properly reproduce the main system trends also for sludge-B, confirming the adsorptive nature of the LCFA inhibitory process with the simulated differences between $T_{B}$ and $C_{B}$ vials (Fig. 3). The ADM1 model, not considering the adsorptive nature of LCFA inhibition, was not able to simulate those differences. These results also confirmed the appropriateness and the bio-physical basis of using bentonite as a synthetic adsorbent (additive) to interfere in the LCFA-adsorption- inhibition process (Palatsi et al., 2012). Moreover, under a slight LCFA-inhibition of the system, the LCFA-M1 model seems to confirm the hypothesis that the acidogenic and the acetoclastic LCFA-inhibition coefficients are invariant within different sludges. However, and in order to predict the evolution of an anaerobic system, the relative LCFA-degraders population structure distribution should be known, or estimated, in advance.

\subsection{LCFA-M2 model calibration. Sludge-A}

The LCFA-M2 model SA is resumed in Table 6, where the main and the total indices are reported for the respective modelparameters. Note that parameter vector $\theta^{4, \mathrm{M} 2}=\left[\mathrm{X}_{\mathrm{c} 18}, \mathrm{X}_{\mathrm{c} 16}\right]$ alone, explains almost the entire variance of the misfit function $J$ (i.e., $87 \%$ ). This implies that $\theta^{4, \mathrm{M} 2}$ can be estimated with great accuracy within the LCFA-M2 model structure and data set $\mathrm{D}_{3, \mathrm{~A}}$. On the other hand, model-parameter vector $\theta^{3, \mathrm{M} 2}=\left[K_{\mathrm{xfa}}\right.$, $\left.r_{\max }, \gamma\right]$ affected $J$ only within the interactions and, thus, it

Table 6 - Sensitivity indexes, LS-estimates and CIs of parameter vectors $\theta^{3, \mathrm{M} 2}$ and $\theta^{4, \mathrm{M} 2}$ for sludge-A (i.e. data set $\left.D_{3, A}\right)$.

\begin{tabular}{llrrcl} 
Parameter & \multicolumn{1}{c}{$g(\theta)$} & \multicolumn{1}{c}{$\mathrm{S}_{\mathrm{i}}$} & \multicolumn{1}{c}{$\mathrm{S}_{\mathrm{Ti}}$} & LS-value & $\mathrm{CI}-95 \%$ \\
\hline $\mathrm{K}_{\mathrm{xfa}}\left(\mathrm{kgCOD} \mathrm{m}^{-3}\right)$ & Unif [1e-4, 2] & 1.14 & 4.92 & 0.260 & \pm 0.035 \\
$r_{\max }\left(\mathrm{d}^{-1}\right)$ & Unif $[1 \mathrm{e}-4,2]$ & 3.07 & 8.98 & 0.066 & \pm 0.024 \\
$\gamma(-)$ & Unif $[1,5]$ & 0.54 & 4.91 & 2.415 & \pm 0.196 \\
$\mathrm{X}_{\mathrm{c} 18}\left(\mathrm{kgCOD} \mathrm{m}^{-3}\right)$ & Unif [1e-4, 5] & 41.16 & 45.51 & 0.300 & \pm 0.063 \\
$\mathrm{X}_{\mathrm{c} 16}\left(\mathrm{kgCOD} \mathrm{m}^{-3}\right)$ & Unif $[1 \mathrm{e}-4,5]$ & 45.91 & 50.74 & 0.053 & \pm 0.006 \\
\hline
\end{tabular}

cannot be accurately determined. However, an estimation of parameter vector $\theta^{3, \mathrm{M} 2}$ is still very important in order to properly fit the collected data. Moreover, for all the parameter-pairs the first-order interaction index $S_{i, j}$ (not shown in Table 6) was negligible. Thus, the presence of higher-order interactions suggests that the interaction structure is quite complex.

The LS-estimates and CI for parameter vectors $\theta^{3, \mathrm{M} 2}$ and $\theta^{4, \mathrm{M} 2}$, for sludge-A, are reported in Table 6 . In all cases, the performed Students t-test indicates a high statistical significance of the estimated parameters. The LS-estimate for parameter $K_{\mathrm{xfa}}$ was $0.260 \mathrm{kgCOD} \mathrm{m}^{-3}$. This value is of the same order of magnitude of the LS-estimate for the LCFA-M1 model (Table 4), and is within its CI. The LS-estimate of the parameter $\gamma$ is higher than one $(\gamma=2.41)$, indicating that, for example, when the average damage of the cell-functionality $D_{\text {xac }}$ is $25 \%$ then we can expect that only $50 \%\left(=(1-0.25)^{2.41}\right)$ of the Ac-degraders will have fully re-activated their methanogenic pathway.

Oleate-degraders are found to be the dominant population in sludge-A (Tables 4 and 6), explaining the higher or longer palmitate-accumulation respect to sludge-B. The model-fit of data set $\mathrm{D}_{3, \mathrm{~A}}$ within the LCFA-M2 model are reported in Fig. 4. Simulation results of the batch experiments with an increasing LCFA concentration (also included in data set $\mathrm{D}_{3, \mathrm{~A}}$ ) are reported in the supporting information, Figure C. From Fig. 4, it can be observed that the misfit of $\mathrm{C} 18_{1}$ is practically the same as for the LCFA-M1 (Fig. 2), since the adsorptionmodel is equivalent and the adsorption process was very quick, when compared with the biological processes. If the model-fits of LCFA-M2 and LCFA-M1 are compared, then the LCFA-M2 model returns a slightly worse result for the oleate concentration on the solid phase $\left(S_{c 18, s} \approx S_{c 18 \text {, ben since }}\right.$ $S_{\text {c18,ben }} \approx 0$ ). However, the LCFA-M2 model equally performed very well, if $C 16_{s}$ was considered. Note that the LCFA overaccumulation artefact, observed when the LCFA-M1 model was used to simulate the sludge-A experiment (Fig. 2), was not present when the LCFA-M2 model is considered (Fig. 4). In fact, from Fig. 4, it can be observed that the period starting from the total $\mathrm{C}_{16}$ s depletion to the re-start of the $\mathrm{CH}_{4}$-production (delay of ten days) was correctly simulated with the LCFA-M2 model. This is because the LCFA-inhibition effect in the LCFAM2 model is not directly dependent on the current value of the concentration of the LCFA-adsorbed on the biomass. Thus, no artificial delay of the LCFA-concentration was necessary in order to correctly fit the methane production measurements. In the present experiments, most the delay period was characterized by an increase of the healthy-state $\mathrm{H}_{\text {xac }}$. The only active bacteria were the acetogens that promoted the Acaccumulation. The simulated Ac-accumulation was quite pronounced in order to satisfy the COD balance (Fig. 4). In particular, at the start-up of the experiment, the simulated degradation of the acetate-pulse was faster than the Ac-measurement seems to suggest. However, the start-up $\mathrm{CH}_{4}$-production data was very well fitted. Because of the highest confidence given to the $\mathrm{CH}_{4}$ measurements (more data available with a low measurement error), the LCFA-M2 modelsimulation probably evidenced a problem with the first few Ac-samples. Note that the LCFA-M1 model was not able to represent correctly the $\mathrm{CH}_{4}$ production at the start-up of the experiment (Fig. 2). 

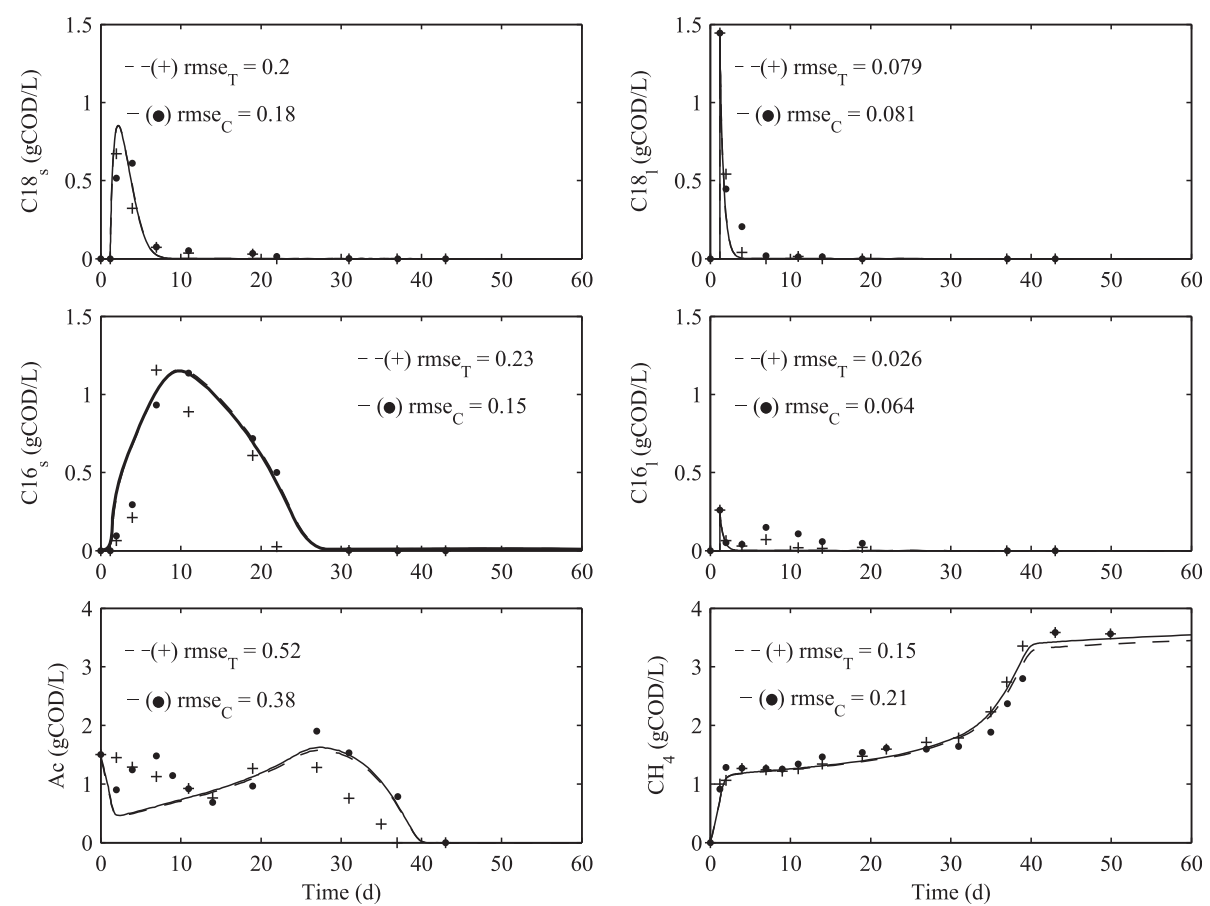

Fig. 4 - Calibration of the LCFA-M2 model with Sludge-A (data set $D_{3, A}$ ). The bentonite addition $\left(T_{A}\right)$ model-outcome (dash lines) and observations (cross dots) are compared with the control-experiment $\left(C_{A}\right)$ model-outcome (continuous lines) and observations (circle dots).

The LCFA-M2 model was superior to the LCFA-M1 model in order to describe the $\mathrm{CH}_{4}$-production data from the toxicity assays (also compare Figure $\mathrm{A}$ and $\mathrm{C}$ in the supporting information) and the LCFA-monitored observations (compare Figs. 2 and 4). However, the LCFA-M2 model used one parameter more than the LCFA-M1 model and, thus, it is expected to be more flexible for data fitting.

Provided that the LCFA-M2 model was calibrated only on data from the experimental set-up of sludge-A, its use (e.g., optimization and control routines) should be constrained only over its calibration domain. Extrapolation with the LCFA-M2 model (calibrated over sludge-A) should be avoided due to its over-parameterized structure. Therefore, if extrapolation is considered, the LCFA-M1 model seems to be more robust then the LCFA-M2 model. However, the LCFA-M2 model performs better with specific interpolation routines since its structure can better describe the LCFA-inhibition process on a lowerscale than the LCFA-M1 model structure.

LCFA-M2 was able to successfully model the impairment between LCFA accumulation and methane production, giving bio-physical explanation to the high methanogenic sensitivity to LCFA inhibition. This new model approximation, as LCFAM1, also confirmed the adsorptive nature of inhibition and the importance of the specific structure of LCFA-degraders population (saturated/unsaturated LCFA) for a successful LCFA degradation process.

\section{Conclusions}

Two new LCFA-inhibition models (i.e., LCFA-M1 and LCFA-M2) were proposed, state-compatible and easy to be integrated into the full ADM1 framework, as a sub-model plug-in. The adsorptive nature of LCFA over granular biomass and specific LCFA-degrader populations were included in both models. The main distinction between the two models is defined by how the LCFA-inhibitory phenomena on acetoclastic methanogens is expressed: i) by a common non-competitive inhibition function (LCFA-M1) or ii) by a new variable that accounts directly for the damage of the cell functionality (LCFA-M2). Both models were tested to reproduce the main trends of a LCFA-inhibited system, operating with a wide range of experimental designs. While the simpler LCFA-M1 model was not able to reproduce correctly the dynamics of the LCFA-degradation, the LCFA-M2 model did. Results from the application of the two proposed models confirmed that the acetoclastic population is more sensitive to the LCFAinhibition than the acidogenic population. In addition, it was evidenced that the distribution of saturated/unsaturated long chain fatty acids degraders plays an important role on the system evolution.

\section{Acknowledgements}

This work was funded by the Spanish Ministry of Science and Innovation (projects CTM 2010-18212 and PSE-1200002009-27).

\section{Appendix A. Supplementary data}

Supplementary data related to this article can be found at http://dx.doi.org/10.1016/j.watres.2012.12.007. 


\section{R E F E R E N C E S}

Alves, M.M., Pereira, M.A., Sousa, D.Z., Cavaleiro, A.J., Picavet, M., Smidt, H., Stams, A.J.M., 2009. Waste lipids to energy: how to optimize methane production from long-chain fatty acids (LCFA). Microbial Biotechnology 2 (5), 538-550.

Angelidaki, I., Ellegard, L., Ahring, B.K., 1999. A comprehensive model of anaerobic bioconversion of complex substrates to biogas. Biotechnology and Bioengineering 63 (3), 363-372.

Batstone, D.J., Keller, J., Angelidaki, I., Kalyuzhnyi, S.V., Pavlostathis, S.G., Rozzi, A., Sanders, W.T.M., Siegrist, H., Vavilin, V.A., 2002. Anaerobic Digestion Model No. 1 (ADM1), IWA Task Group for Mathematical Modelling of Anaerobic Digestion Processes. IWA Publishing, London.

Beccari, M., Majone, M., Riccardi, C., Savarese, F., Torrisi, L., 1999. Integrated treatment of olive oil mill effluents: effect of chemical and physical pretreatment on anaerobic treatability. Water Science and Technology 40 (1), 347-355.

Desbois, A.P., Smith, V.J., 2010. Antibacterial free fatty acids: activities, mechanisms of action and biotechnological potential. Applied Microbiology and Biotechnology 85 (6), 1629-1642.

Dochain, D., Vanrolleghem, P.A., 2001. Dynamical Modelling and Estimation in Wastewater Treatment Processes. IWA Publishing, London, UK.

Hanaki, K., Matsuo, T., Nagase, M., 1981. Mechanisms of inhibition caused by long chain fatty acids in anaerobic digestion process. Biotechnology and Bioengineering 23 (7), 1591-1610.

Hatamoto, M., Imachi, H., Yashiro, Y., Ohashi, A., Harada, H., 2007. Diversity of anaerobic microorganisms involved in longchain fatty acids degradation in methanogenic sludges as revealed by RNA-based stable isotope probing. Applied and Environmental Microbiology 73 (13), 4119-4127.

Hwu, S.H., Tseng, S.K., Yuan, C.Y., Kulik, Z., Lettinga, G., 1998. Biosorption of long-chain fatty acids in UASB treatment process. Water Research 32 (5), 1571-1579.

Kim, B.H., Gadd, G.M., 2008. Bacterial Physiology and Metabolism. Cambridge University Press, New York.

Kuang, Y., Pullammanappallil, P., Lepesteur, M., Ho, G.-E., 2006. Recovery of oleate-inhibited anaerobic digestion by addition of simple substrates. Journal of Chemical Technology \& Biotechnology 81 (6), 1057-1063.

Lalman, J.A., Bagley, D.M., 2001. Anaerobic degradation and methanogenic inhibitory effects of oleic and stearic acids. Waster Research 35 (12), 2975-2983.

Lokshina, L.Y., Vavilin, V.A., Salminen, E., Rintala, J., 2003. Modeling of anaerobic degradation of solid slaughterhouse waste. Inhibition effect of long-chain fatty acids or ammonia. Applied Biochemistry and Biotechnology 109 (1-3), 15-32.

Mouneimne, A.H., Carrère, H., Bernet, J.P., Delgenès, J.P., 2004. Effect of the addition of bentonite on the anaerobic biodegradability of solid fatty wastes. Environmental Technology 25 (4), 459-469.

Nielsen, H.B., Ahring, B.K., 2006. Responses of the biogas process to pulses of oleate in reactors treating mixtures of cattle and pig manure. Biotechnology and Bioengineering 95 (1), 96-105.

Oakley, J.E., O’Hagan, A., 2004. Probabilistic sensitivity analysis of complex models: a Bayesian approach. Journal of the Royal Statistical Society Series B (Statistical Methodology) 66 (3), 751-769.

Palatsi, J., Affes, R., Fernandez, B., Pereira, A., Alves, M., Flotats, X., 2012. Influence of adsorption and anaerobic granular sludge characteristics on long chain fatty acids inhibition process. Water Research 46 (16), 5268-5278.

Palatsi, J., Illa, J., Prenafeta-Boldú, F.X., Laureni, M., Fernandez, B., Angelidaki, K., Flotats, X., 2010. Long-chain fatty acids inhibition and adaptation process in anaerobic thermophilic digestión: batch tests, microbial community structure and mathematical modelling. Bioresource Technology 101 (7), 2243-2251.

Palatsi, J., Laureni, M., Andrés, M.V., Flotats, X., Nielsen, H.B., Angelidaki, I., 2009. Recovery strategies from long-chain fatty acids inhibition in anaerobic thermophilic digestion of manure. Bioresource Technology 100 (20), 4588-4596.

Pereira, M.A., Pires, O.C., Mota, M., Alves, M.M., 2005. Anaerobic biodegradation of oleic and palmitic acids: evidence of mass transfer limitations caused by long chain fatty acid accumulation onto the anaerobic sludge. Biotechnology and Bioengineering 92 (1), 15-23.

Pereira, M.A., Pires, O.C., Mota, M., Alves, M.M., 2002. Anaerobic degradation of oleic acid by suspended sludge: identification of palmitic acid as a key intermediate. Water Science and Technology 45 (10), 139-144.

Pereira, M.A., Sousa, D.Z., Mota, M., Alves, M.M., 2004. Mineralization of LCFA associated with anaerobic sludge: kinetics, enhancement of methanogenic activity and effect of VFA. Biotechnology and Bioengineering 88 (4), 502-511.

Picioreanu, C., Batstone, D.J., van Loosdrecht, M.C.M., 2005. Multidimensional modelling of anaerobic granules. Water Science and Technology 52 (1-2), 501-507.

Ratto, M., Tarantola, S., Saltelli, A., 2001. Sensitivity analysis in model calibration: GSA-GLUE approach. Computer Physics Communication 136 (3), 212-224.

Rinzema, A., Boone, M., van Knippenberg, K., Lettinga, G., 1994. Bactericidal effect of long chain fatty acids in anaerobic digestion. Water Environmental Research 66 (1), 40-49.

Rodriguez-Fernandez, M., Egea, J.A., Banga, J.R., 2006. Novel metaheuristic for parameter estimation in nonlinear dynamic biological systems. BMC Bioinformatics 7, 483.

Rosen, C., Jeppsson, U., 2006. Aspects on ADM1 Implementation within the BSM2 Framework. Department of Industrial Electrical Engineering and Automation, Lund University, Lund, Sweden. Tech. Report, (CODEN: LUTEDX/TEIE-7224/1-35/ 2006).

Salminen, E., Rintala, J., Lokshina, L.Ya., Vavilin, V.A., 2000. Anaerobic batch degradation of solid poultry slaughterhouse waste. Water Science and Technology 41 (3), 33-41.

Saltelli, A., Annoni, P., Azzini, I., Campolongo, F., Ratto, M., Tarantola, S., 2010. Variance based sensitivity analysis of model output design and estimator for the total sensitivity index. Computer Physics Communications 181 (2), 259-270.

Shin, H.-S., Kim, S.-H., Lee, C.-Y., Nam, S.-Y., 2003. Inhibitory effects of long-chain fatty acids on VFA degradation and lbetaoxidation. Water Science and Technology 47 (10), 139-146.

Sobol', I.M., 1976. Uniformly distributed sequences with an addition uniform property. U.S.S.R. Computational Mathematics and Mathematical Physics 16, 236-242.

Sousa, D.Z., Pereira, M.A., Alves, J.I., Smidt, H., Stams, A.J.M., 2008. Anaerobic microbial LCFA degradation in bioreactors. Water Science and Technology 57 (3), 439-444.

Sousa, D.Z., Pereira, M.A., Stams, A.J.M., Alves, M.M., 2007. Microbial communities involved in anaerobic degradation of unsaturated or saturated long chain fatty acids (LCFA). Applied Environmental Microbiology 73 (4), 1054-1064.

Valentine, D.L., 2007. Adaptations to energy stress dictate the ecology and evolution of the Archaea. Nature Reviews Microbiology 5, 316-323. 